\title{
AdGMCAIX-transduced Autologous Dendritic Cells
}

National Cancer Institute

\section{Source}

National Cancer Institute. AdGMCAIX-transduced Autologous Dendritic Cells. NCI

Thesaurus. Code C105809.

Autologous dendritic cells (DCs) transduced with a recombinant, replication-defective adenoviral vector expressing the fusion gene granulocyte-macrophage colonystimulating factor (GM-CSF) and carbonic anhydrase IX (CA-IX or CA9) (GMCA-9), with potential immunomodulating activity. The autologous DCs are transduced ex vivo and express the GMCA-9 fusion protein on the cell surface. Upon intradermal administration of the AdGMCAIX-transduced autologous DCs back into the patient, the DCs activate the immune system to both mount a cytotoxic T lymphocyte-mediated response against tumor cells positive for the CA9 antigen, and generate memory T cells. This may result in decreased tumor growth. CA9, also known as G250, is a renal cell carcinoma (RCC)associated antigen and a member of the carbonic anhydrase family that contains a human leukocyte antigen (HLA)-A2.1-restricted epitope; it is found in a majority of renal cell carcinomas while absent in most normal tissues. The cytokine GM-CSF enhances the immunogenicity of CA9-based DC vaccines. 